\section{Endoscopic ultrasound-guided drainage of an intra-abdominal abscess: a new therapeutic window to the left subphrenic space}

A 67-year-old woman was admitted to the hospital for the first time due to obstructive jaundice. Cholecystectomy and choledochotomy with T-drainage were carried out, and 6 days after the operation, an exploratory laparotomy and retroperitoneal necrosectomy were done due to acute hemorrhagic necrotic pancreatitis. One month later, endoscopic ultrasonography (EUS) and multislice computed tomography demonstrated an encapsulated left subphrenic abscess, $10 \mathrm{~cm}$ in diameter (Figure 1,2). It was decided to carry out EUS-guided drainage, as the abscess was directly adjacent to the stomach and it was considered that EUS would provide a much shorter and safer approach. The procedure was conducted with the Giovannini drainage set and with linear-array ultrasound guidance (Figure 3). After the drainage, the patient's fever ceased, the C-reactive protein level dropped significantly, and the white blood count showed normal values. The next day, transabdominal ultrasonography demonstrated a residual crescent-shaped abscess cavity measuring $44 \times 59 \mathrm{~mm}$. Six days after the drainage, a check-up endoscopy showed that the stent was patent (Figure 4). Unfortunately, the patient died of multiple organ failure 8 days after the drainage procedure.

EUS-guided pseudocystogastrostomy has become almost a routine procedure at some centers [ $1-3]$. Seewald et al. have described successful EUS-guided drainage of left-sided subphrenic and hepatic abscesses $[3,4]$. EUS should be regarded as a first-choice method for draining leftsided subphrenic abscesses, especially in critically ill patients. The usual complication of abscess drainage is blockage of the stent, and many authors have therefore suggested that several stents should be placed.

In the present case, the patient's clinical status improved dramatically after the initial single-stent drainage. The intention was to place a nasocystic drain as a second step, to ensure constant irrigation

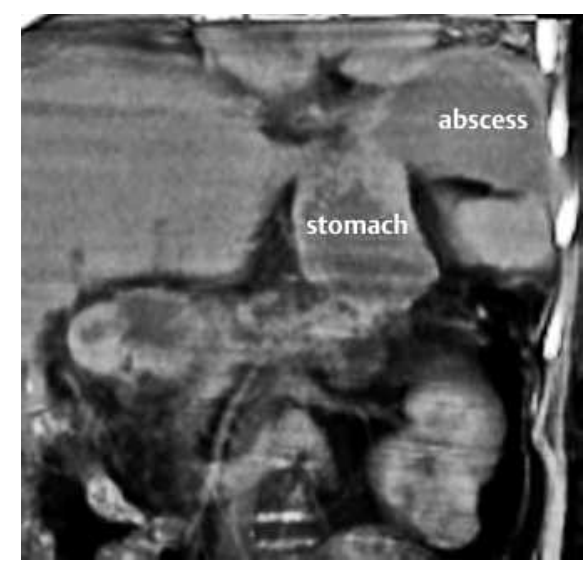

Figure 1 Multislice computed tomography of the well-encapsulated left-sided subphrenic abscess adjacent to the stomach.
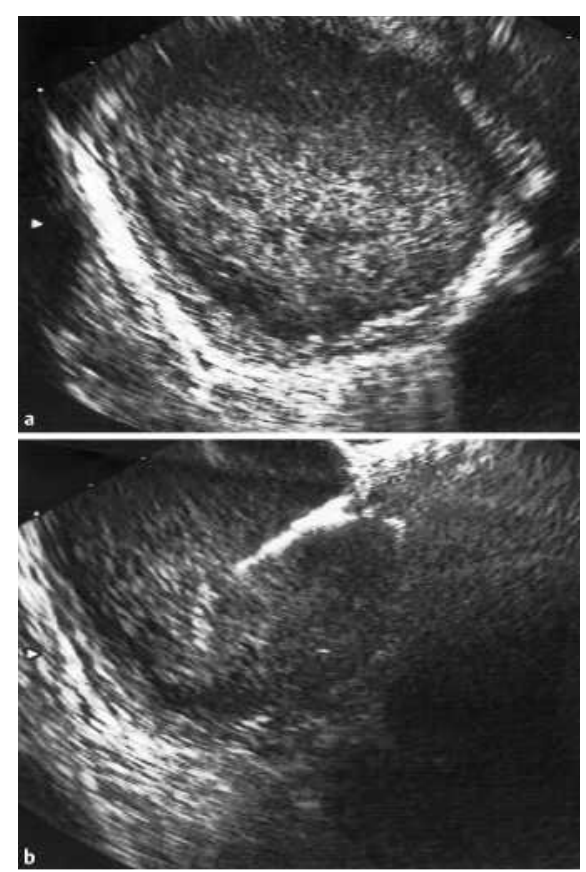

Figure 2 a Endoscopic ultrasonography provided good visualization of the subphrenic abscess. b Positioning of the guide wire in the abscess.

with a saline infusion, which we consider to be the best option for improving stent patency. Unfortunately, the patient's clinical condition suddenly deteriorated.

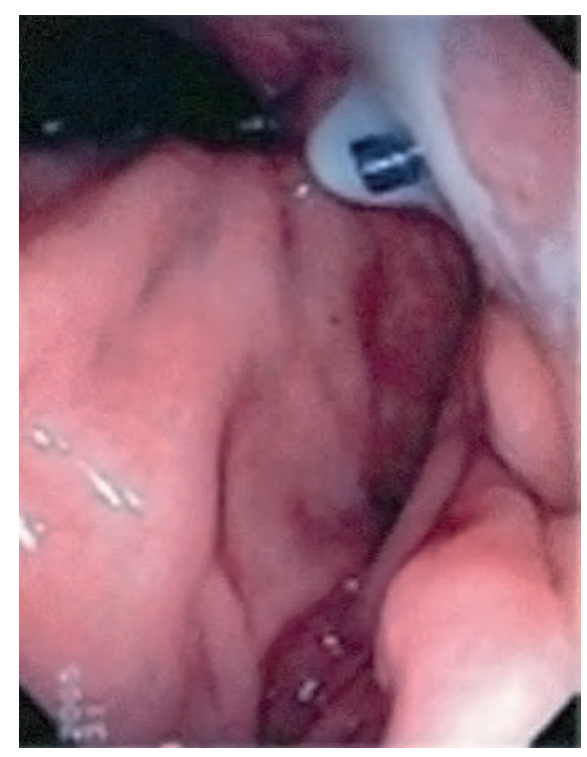

Figure 3 Endoscopic view of the gastric fundus, with pus draining through the catheter.

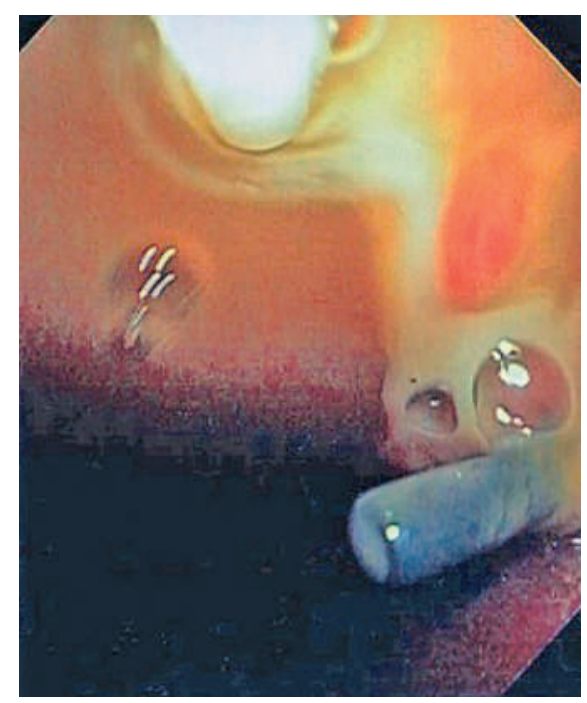

E17

Figure 4 Six days after the drainage procedure, a check-up esophagogastroduodenoscopy shows that the stent is patent in the gastric fundus.

Endoscopy_UCTN_Code_CCL_1AF_2AG_3AC Endoscopy_UCTN_Code_TTT_1AR_2AC 
N. Rustemovićc ${ }^{1}$, M. Opačić ${ }^{1}$, T. Bates', R. Ostojić ${ }^{1}$, R. Štern Padovan²,

R. Pulanić ${ }^{1}$, B. Vucelić ${ }^{1}$

${ }^{1}$ Dept. of Gastroenterology, Zagreb University Hospital Center, Zagreb, Croatia

2 Dept. of Radiology, Zagreb University Hospital Center, Zagreb, Croatia.
References

${ }^{1}$ Kahaleh M, Yoshida C, Kane L, Yeaton P. EUS drainage of a mediastinal abscess. Gastrointest Endosc 2004; 60: 158 - 160

${ }^{2}$ Kahaleh M, Wang P, Shami VM et al. Drainage of gallbladder fossa fluid collections with endoprosthesis placement under endoscopic ultrasound guidance: a preliminary report of two cases. Endoscopy 2005; 37 : 393-396

${ }^{3}$ Seewald S, Imazu H, Omar S et al. EUS-guided drainage of hepatic abscess. Gastrointest Endosc 2005; 61: 495-498

${ }^{4}$ Seewald S, Brand B, Omar S et al. EUS-guided drainage of subphrenic abscess. Gastrointest Endosc 2004; 59: 578-580
Corresponding author

\section{N. Rustemović, M.D., Ph.D.}

Dept. of Gastroenterology

Zagreb University Hospital Center

Kišpatićeva 12

10000 Zagreb

Croatia

Fax: $\quad+385-1-2420100$

E-mail: nadan.rustemovic@zg.htnet.hr 